\title{
Chapter 12 \\ Strategic Aggregation of Universities \\ in Spain: The Spanish Program International \\ Campus of Excellence and the Experience of the Technical University of Madrid
}

\author{
Luis Delgado and Gonzalo León
}

\subsection{Introduction}

In 2008 the Spanish government launched a new strategy to foster the modernization and internationalization of the Spanish university system, the Strategy University 2015 (SU 2015). ${ }^{1}$ The main goal of this initiative was to allow Spanish universities to fulfil and exploit their potential to contribute to the development of a knowledge-based economy and society.

With 2015 as its time horizon, the strategy, adapted to the specific characteristics of the Spanish universities, was aimed at addressing the recommendations of the Modernization Agenda of Universities launched by the European Commission in $2006,{ }^{2}$ namely promoting the development of highly internationalised, well managed and well funded universities, with a solid education and research basis, contributing to the global production of knowledge and to the sustainable economic development and innovation of their territorial environments. As schematised in (Fig. 12.1), the strategy proposed four main axes and several strategic lines: Missions; People; Institutions and Environment.

\footnotetext{
${ }^{1}$ Strategy University 2015. Modernizing the University. June 2010. Ministry of Education. Spain. ${ }^{2}$ COM (2006) 208 final "Delivering the Modernization Agenda for Universities: education, research and innovation".

L. Delgado $(\bowtie)$

Ministry of Education, Culture and Sport, Madrid, Spain

e-mail: luism.delgado@mecd.es

G. León $(\square)$

Technical University of Madrid (UPM), Madrid, Spain

e-mail: gonzalo.leon@upm.es 


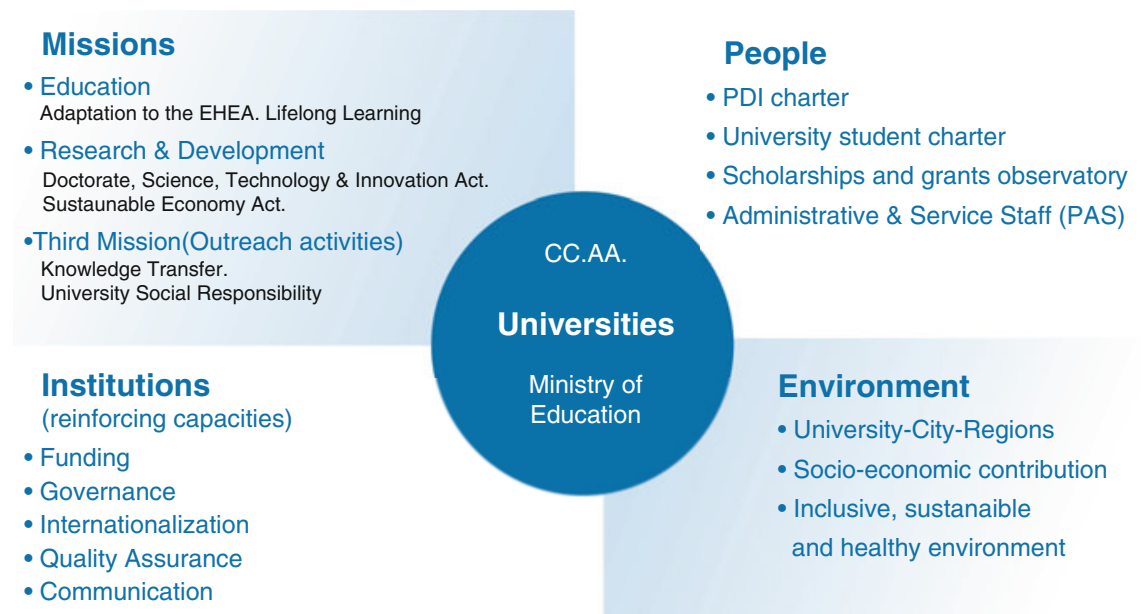

Fig. 12.1 Strategic axes and lines of Strategy University 2015

Within this strategy a new programme, entitled International Campus of Excellence (CEI) was launched in 2008. The main aim of the CEI programme was to position the top Spanish University Campuses among the best of Europe, promoting their international recognition and supporting the strengths of the Spanish university system. The purpose of this paper is to present the main results of the CEI program concerning the main alliances and strategic aggregations resulting after three consecutive CEI calls at 2009, 2010 and 2011.

An overview of the National context will be given. Then, the main characteristics of the CEI program will be presented as an introduction to the case-studies described. Two different perspectives will be used. First from the perspective of the policy maker, a cross-case commentary on two strategic merger cases representing different types of campuses will be presented. This will include information provided by the CEI projects, ${ }^{3}$ details of the institutions involved in the process, the rationale for the aggregation, the process of change as well as the progress and outcomes achieved in each case. An in-depth study of a thematic campus involving a Technical University on technology will be given from the perspective of the university involved in the campus. Finally, the main conclusions and lessons learned will be addressed.

\footnotetext{
${ }^{3}$ Special thanks are giving to the Coordinators of BKC, Prof. Manuel Barranco and Prof. José Dorronsoro from UAM-CSIC, who provided information on their respective projects.
} 


\subsection{National Context}

The challenges faced by the Spanish university system are common to other EU countries, though with some special characteristics because of the largely decentralised administrative structure of the country and the large impact on the Spanish economy of the economic crisis.

The Spanish University System is composed of 81 universities of which 50 public, developing their activities in 236 university campuses scattered all over Spain. Catalonia, Madrid and Andalusia account for almost $75 \%$ of the total university campuses. There was a tremendous increase in the number of universities over the last 30 years, with a growth in the number of universities from 28 in 1975 to 73 in 2005 , due to the need to increase access to university education all over Spain, as well as to improve the transfer of education competences to the regions. During the academic course 2011-2012 there were around 1,600,000 university students, including the third cycle, of which still around 900,000 were in the former 1st and 2nd cycle structure, 550,000 were bachelor students, 100,000 Masters students and 30,000 $\mathrm{PhD}$ candidates. ${ }^{4}$

\subsubsection{Teaching}

The three level structure adopted under the EHEA consists of a 4 year (240 ECTS) Bachelor programme (1st cycle), a 2nd cycle or Master level programme with a duration of 1-2 years (60 to 240 ECTS) and the 3rd cycle the Doctorate level on advanced training in research, not measured in ECTS. This 3rd cycle is structured around Doctoral Schools as Units created by one or several universities in possible collaboration with other national or international $\mathrm{R}+\mathrm{D}+\mathrm{I}$ bodies, centres, institutions or entities, with the objective of the organization of the $\mathrm{PhD}$ in one or several knowledge domains or with interdisciplinary character.

In the academic year 2011-2012 Spanish universities offered a total of 2,413 Bachelor's degrees and 2,758 Master' degrees, showing an excessive uniformity of the study offer with some duplication and very little differentiation.

\subsubsection{Research}

In the area of research and development $(R \& D)$, Spain, though still a catching-up country in the EU in terms of R\&D Intensity (1.33\% of GDP in 2011), made a

\footnotetext{
${ }^{4}$ Datos y Cifras del Sistema Universitario. Curso 2011. Ministerio de Educación.
} 
strong effort in the years to 2008 to increase its investments in R\&D (1.35\% of GDP). Thus, within the period 2002-2006 the real growth of Gross Domestic Expenditure on R\&D (GERD) in Spain was of $61.9 \%$ (14.8\% in EU-27), ${ }^{5}$ with a share of $3.1 \%$ of the world scientific publications, above the share of Spain in the global GDP (2.7\%). Spanish universities accounted for $28.2 \%$ of the total GERD in 2011 , representing an increase of $11.8 \%$ as compared to $2007 .{ }^{6}$ Since 2008 , due to the impact of the economic crisis there has been a decrease in R\&D Intensity from $1.35 \%$ of GDP in 2008 down to $1.33 \%$ in 2011 but with an increase in the university share of the GERD (26.8\% in 2008 and $28.2 \%$ in 2011).

Universities are the second major employer after business of researchers in Spain with 80,900 full-time equivalent researchers (37.6 \% of the total). Within the National Plan of R\&D in the area of Fundamental Research, universities participate in $75 \%$ of the awarded projects receiving $63.5 \%$ of the total budget in 2008. After businesses, they are the second research performer in the Seventh Framework Programme of Research and Technological Development (FP7), accounting for $24.6 \%$ of the competitive funding coming from FP7.

In the international context, Spain has very few universities acting as major research centres of scientific reference, with 11 universities in the Top-500 (2.2\% compared with a share of $2.7 \%$ in the global GDP) of the Shangai ranking. The international mobility of Spanish university students $(1.8 \%)$ and the enrolment of foreign undergraduate students $(3.6 \%)$ in Spanish universities are below the average for OECD countries, ${ }^{8}$ though at postgraduate level the foreign enrolment increases up to $16.9 \%$ at Masters level and up to $24.7 \%$ at Doctoral level.

\subsubsection{Challenges and Weaknesses}

Though a large proportion of Spanish universities have almost completed the curricular reform within the so-called Bologna process to have a common framework for university education within the European Higher Education Area (EHEA), other reforms of the Modernization Agenda for Universities, mainly the governance reform, involving aspects of links with businesses, internationalisation, social dimension, quality, etc. and the funding reform have still to be completed.

Spanish research universities need to adapt to a changing global environment in which knowledge is the key driver of socioeconomic development, driving improvements in certain key areas. They need:

\footnotetext{
${ }^{5}$ Science, Technology and Competitiveness key figures report 2008/2009. EUR 23608 EN.

${ }^{6}$ Statistics on R\&D Activities 2011. National Institute of Statistics.

${ }^{7}$ Indicadores del Sistema español de Ciencia y Tecnología. 2012. Ministerio de Economía y Competitividad.

${ }^{8}$ Education at a glance. OCDE Report 2011.
} 
Fig. 12.2 Student mobility and foreign enrolment at undergraduate level in Spain

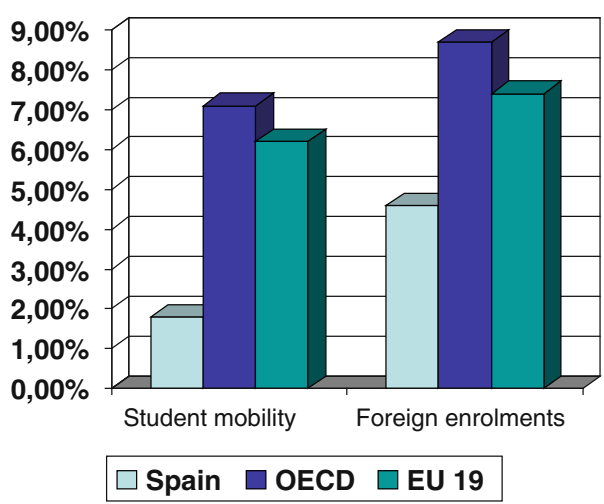

- To pursue excellence in strategic knowledge domains, increasing their participation in global research and innovation networks, interacting with other universities, research centres and business in a sort of knowledge ecosystems or education, research and innovation communities, where they can interact with other knowledge-related agents, develop and excel.

- To differentiate and specialise, adapting their training and research agendas, responding to the increasing complexity and inter and trans-disciplinary nature of research, and to the grand societal challenges.

- To increase their level of international activities in education and research (joint degrees, doctoral schools, joint research programmes, etc.), boosting the international mobility of their students and staff, attracting, retaining and motivating the best talents (Fig. 12.2).

In 2009 when the first CEI call was launched, there was a need to modernize Spanish universities simultaneously with the process of adaptation to the European Higher Education Area. This was at the core of a very hard economic crisis having an impact on the public budget available for higher education.

\subsection{The International Campus of Excellence Program}

To address the major challenges and weaknesses detected in the diagnosis of the Spanish university system made by SU 2015, the CEI program was intended to promote strategic aggregations among universities and other research institutions and business placed within the campus, to develop university-centred knowledge clusters, acting as local hubs of international excellence and contributing to the regional economic development, social cohesion and employment, by:

- Introducing a new funding instrument at institutional level to support new forms of cooperation - competition at national level among universities and other knowledge-related agents, around a new concept of university campus. 
- Strengthening cooperation with other knowledge-related agents.

- Fostering the contribution to the development of a new model of sustainable, knowledge-based socioeconomic growth.

The main declared objectives of CEI were:

1. To improve the international visibility of the best Spanish university campus through the promotion of strategic aggregations to reach critical mass and excellence;

2. To promote the diversification and specialisation of universities and

3. To promote the development of innovative regions whose economic development is based on knowledge.

The CEI program developed a new concept of university campus based on three key concepts: internationalization, aggregation and excellence.

Other important dimension of this campus' concept ${ }^{9}$ is to create territorial environments of university life, socially and economically integrated within the urban or regional territories. The campus will pay special attention to achieve a high quality of services and environmental sustainability, i.e. healthy and sustainable campus that can contribute to increase the attractiveness of the territory for international students, academics and researchers, as well as for knowledge-related investments.

Under the CEI program the universities had to present strategic plans to transform their university campuses into CEI. The proposals were evaluated in a two stage peer review process, first by a National Technical Commission composed by independent academic and research experts making an initial selection of the projects, passing to the 2nd phase where they were publically presented and evaluated by an International Commission who finally selected the projects to be awarded with the CEI label (Fig. 12.3).

The public presentation of the CEI proposals was a somehow media event with more than 600 attendants each year, representing the major stakeholders: academics from the universities, including Rectors of the CEI proposals, political representatives at national (Parliament, Senate, political parties), regional (Presidents and Education and Research Counsellors of the regions), business with Presidents of large companies participating in the proposed aggregations, socioeconomic agents (Unions, Social Councils), etc.

The evaluation criteria included the appraisal of three transversal dimensions, mainly the quality and sustainability of the strategic aggregation, internationalization and specialization and of the four strategic axes:

1. Teaching improvement and adaptation to the European Higher Education Area;

2. Scientific quality and knowledge transfer;

\footnotetext{
${ }^{9}$ Developing International campuses of excellence. Màrius Rubiralta and Luis Delgado. Ministry of Education, Spain. CELE Exchange 2010/4. OECD 2010.
} 


\section{International Campus of Excellence}

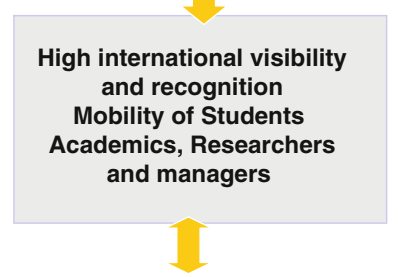

INTERNATIONALIZATION
Strategic aggregations of universities, R\&D Centres, Firms and other Knowledge -related agents Knowledge and Innovation Ecosystems Excellence in Teaching,
R\&D and Innovation Social Model of the Campus Sustainability Relevance to the territorial development

Fig. 12.3 The key concepts of the CEI program: internationalization, aggregation, excellence

3. Transformation of the campus to develop an integral social model and

4. Interaction with the territorial environment.

After some preparatory actions in 2008 signing agreements with the regions to involve the Autonomous Communities in the programme, three consecutive calls were launched in 2009, 2010 and 2011 involving two main subprograms: Excellence and Strengthening. The CEI Excellence subprogram awarded CEI excellence levels and funding through loans via the Autonomous Communities to specific projects developing institutional strategies to transform specific campuses into CEI in a 4 years process.

The CEI Strengthening subprogram (in 2010 and 2011, once the first CEI labels were awarded in 2009) included specific funding lines through direct grants to universities to strengthen concrete aspects of the CEI projects.

It consisted of two main parts: Consolidation of CEI with public funding and Public-Private Partnership (PPP) including private funding (see Table 12.1). This PPP modality of the CEI Strengthening subprogram selected partial aspect of the CEI projects to be financed through an agreement between the former Ministry of Education and private entities on the aspects shown in Table 12.1.

The total funding of the CEI programme in the period 2008-2011, since the launch of the preparatory actions in 2008 until the last call in 2011, has reached 686.7 million Euros with an average of 171.6 million Euros per year, of which $84.5 \%$ are loans awarded to the Autonomous Communities where the universities are located to be then transferred to the CEI projects, and $15.5 \%$ are direct grants to the universities.

The programme was originally managed by the former Ministry of Education, currently the Ministry of Education, Culture and Sport (MECD) in collaboration with the former Ministry of Science and Innovation, currently the Ministry of Economy and Competitiveness, and the support of the Autonomous Communities. 
Table 12.1 Specific funding lines under the CEI strengthening program

\begin{tabular}{|c|c|c|}
\hline & Consolidation & Public-private partnership \\
\hline \multirow[t]{6}{*}{ Internationalization } & Trans border campus & \\
\hline & International bridges & \\
\hline & $\begin{array}{l}\text { Setting of world-class centres } \\
\text { abroad }\end{array}$ & \\
\hline & $\begin{array}{l}\text { Organization of top international } \\
\text { events in the priority areas }\end{array}$ & \\
\hline & $\begin{array}{l}\text { Participation in international pro- } \\
\text { jects, associations and networks on } \\
\text { education, research and innovation }\end{array}$ & \\
\hline & $\begin{array}{l}\text { Institutional strategies and pro- } \\
\text { grams on learning and knowledge } \\
\text { mobility }\end{array}$ & \\
\hline \multirow[t]{4}{*}{$\begin{array}{l}\text { Academic } \\
\text { excellence }\end{array}$} & $\begin{array}{l}\text { Adaptation to the European higher } \\
\text { education area }\end{array}$ & Pedagogy and leadership \\
\hline & Attracting and incentivising talent & $\begin{array}{l}\text { Organization of meetings with } \\
\text { Nobel Prizes }\end{array}$ \\
\hline & $\begin{array}{l}\text { Development of vocational educa- } \\
\text { tion and training centres }\end{array}$ & Scientific summer campus \\
\hline & $\begin{array}{l}\text { Creation of International and } \\
\text { Interuniversity Doctoral and Post- } \\
\text { graduated Schools }\end{array}$ & \\
\hline $\begin{array}{l}\text { Coordination of } \\
\text { higher education }\end{array}$ & Setting up of collaboration networks & \\
\hline $\begin{array}{l}\text { Governance and } \\
\text { management of the } \\
\text { CEI }\end{array}$ & Governance & Training of CEI managers \\
\hline \multirow{3}{*}{$\begin{array}{l}\text { Entrepreneurship } \\
\text { and technological } \\
\text { development }\end{array}$} & \multirow[t]{3}{*}{ Promotion of innovative ecosystems } & Promotion of entrepreneurship \\
\hline & & Applied research \\
\hline & & Sustainable labs \\
\hline Creativity & & $\begin{array}{l}\text { Creative parks, artistic creation } \\
\text { networks }\end{array}$ \\
\hline \multirow[t]{5}{*}{$\begin{array}{l}\text { Excellence towards } \\
\text { the environment }\end{array}$} & $\begin{array}{l}\text { Creation and rehabilitation of uni- } \\
\text { versity housing }\end{array}$ & $\begin{array}{l}\text { Technological environment to } \\
\text { facilitate access to ITC }\end{array}$ \\
\hline & Diffusion of knowledge & $\begin{array}{l}\text { Rehabilitation and adaptation of } \\
\text { university areas improving acces- } \\
\text { sibility and inclusion of disabled } \\
\text { people }\end{array}$ \\
\hline & Modernisation of labs & $\begin{array}{l}\text { Use of new technological } \\
\text { resources improving accessibility } \\
\text { and inclusion }\end{array}$ \\
\hline & $\begin{array}{l}\text { Development of virtual platforms } \\
\text { for employability }\end{array}$ & \multirow[t]{2}{*}{$\begin{array}{l}\text { Inclusive summer campuses. } \\
\text { Campus without limits }\end{array}$} \\
\hline & Improvement of sport spaces & \\
\hline
\end{tabular}




\subsubsection{Results}

The balance of the results of the three consecutive CEI calls ${ }^{10}$ is summarised here.

Thirty two (32) excellence CEI labels out of a total of 236 campuses in Spain were awarded in 2009, 2010 and 2011, in two main categories: 15 CEI: international Campus of Excellence at global level and 17 CEIR: International Campus of Excellence of regional (in the European context) level (see Table 12.2).

As indicated in (Table 12.2), the concept of campus established in the programme leads to certain universities being involved in one or more CEI. This is due to the fact that it is not the whole university which is involved in CEI projects, but only the part of the university related to the specific priorities of the relevant CEI project.

All the CEI labels are initially awarded on a provisional basis to projects that, in the opinion of the International Commission evaluating the proposals, have a high potential to achieve a level of international excellence by the end of the 4 year duration of the projects. An annual evaluation of the progress of the project is carried out every year with possible consequences for renewal or removal of the label.

The geographical distribution of the current CEI and CEIR is provided in (Fig. 12.4).

The thematic specialization of the CEI projects is presented in (Table 12.3)

\subsection{Cross-Case Commentary of Two Cases: Barcelona Knowledge Campus and Campus UAM + CSIC}

The two cases studied here from the perspective of the policy maker include an urban campus in Barcelona, Barcelona Knowledge Campus ${ }^{11}$; and another related to the aggregation of a university and a research centre, Campus UAM + CSIC ${ }^{12}$ :

- BKC, CEI project involving two complementary universities located close to each other in Barcelona with major facilities and buildings along the Diagonal street: University of Barcelona, UB, and the Technical University of Catalonia, UPC. No significant previous attempts to merge or form alliances among UB and UPC until the CEI programme encouraged strategic aggregation.

- UAM + CSIC, CEI project involving the Autonomous University of Madrid (UAM) and Spain's National Research Council (CSIC), specifically the 10 CSIC centres located within the UAM campus, together with other

\footnotetext{
${ }^{10}$ Balance de tres años del programa Campus de Excelencia Internacional. Memoria 2008-2011. Ministerio de Educación.

${ }^{11}$ http://bkc.ub.upc.edu/

${ }^{12} \mathrm{http} / / /$ campusexcelencia.uam-csic.es/ss/Satellite/CampusExcelenciaUAM/es/home.htm
} 
Table 12.2 List of the 15 CEI and 17 CEIR awarded in 2009, 2010 and 2011

\begin{tabular}{|c|c|c|}
\hline Call & CEI project & Universities \\
\hline \multirow[t]{2}{*}{2009} & \multirow[t]{2}{*}{ Barcelona Knowledge Campus } & U. de Barcelona \\
\hline & & U. Politécnica de Cataluña \\
\hline \multirow[t]{2}{*}{2009} & \multirow{2}{*}{$\begin{array}{l}\text { Campus Moncloa. La Energía de la } \\
\text { diversidad }\end{array}$} & U. Complutense de Madrid \\
\hline & & U. Politécnica de Madrid \\
\hline 2009 & Campus Carlos III & U. Carlos III \\
\hline 2009 & $\begin{array}{l}\text { UAB CEI: Apuesta por el } \\
\text { Conocimiento y la Innovación }\end{array}$ & U. Autónoma de Barcelona \\
\hline 2009 & CEI UAM-CSIC & U. Autónoma de Madrid, CSIC \\
\hline 2010 & Andalucía TECH & U. de Sevilla. U. de Málaga \\
\hline 2010 & $\begin{array}{l}\text { Campus Energía UPC: Energía para la } \\
\text { Excelencia }\end{array}$ & U. Politécnica de Cataluña \\
\hline 2010 & $\begin{array}{l}\text { Campus IBERUS: CEI del valle del } \\
\text { Ebro }\end{array}$ & $\begin{array}{l}\text { U. Zaragoza. U. de La Rioja. U. de Lleida. } \\
\text { U. Pública de Navarra }\end{array}$ \\
\hline 2010 & Campus UPF - Icària Internacional & U. Pompeu Fabra \\
\hline 2010 & CEI Montegancedo I2Tech & U. Politécnica de Madrid \\
\hline 2010 & $\begin{array}{l}\text { EUSKAMPUS. Una Universidad, un } \\
\text { País, un Campus }\end{array}$ & U. del País Vasco \\
\hline 2010 & $\begin{array}{l}\text { Health Universitat de Barcelona Cam- } \\
\text { pus HUBc }\end{array}$ & U. de Barcelona \\
\hline 2010 & VLC/Campus-Valencia CEI & U. de Valencia. U. Politécnica de Valencia \\
\hline 2011 & Horizonte 2015 & U. de Navarra \\
\hline 2011 & Campus Habitat $5 \mathrm{U}$ & $\begin{array}{l}\text { U. Politécnica de Valencia. U. de Valencia. } \\
\text { U. Jaume I de Castellón. U. de Alicante. } \\
\text { U. Miguel Hernández de Elche }\end{array}$ \\
\hline Call & CEIR project & Universities \\
\hline 2009 & $\begin{array}{l}\text { Campus de Excelencia Agroalimentaria } \\
\text { CeiA3 }\end{array}$ & $\begin{array}{l}\text { U. de Córdoba, U. de Almería, U. de Jaén, } \\
\text { U. de Huelva, U. de Cádiz }\end{array}$ \\
\hline 2009 & Cantabria Campus Internacional & U. de Cantabria \\
\hline 2009 & Campus Vida & U. Santiago de Compostela \\
\hline 2009 & AD FUTURUM & U. de Oviedo \\
\hline 2010 & Campus Biotic Granada & U. de Granada \\
\hline 2010 & CEI Catalunya Sud & U. Rovira i Virgili \\
\hline 2010 & Campus do Mar "Knowledge in depth" & $\begin{array}{l}\text { U. de Vigo, U. de La Coruña, U. Santiago de } \\
\text { Compostela }\end{array}$ \\
\hline 2010 & Campus Mare Nostrum 37/38 & U. Murcia. U. Politécnica de Cartagena \\
\hline 2010 & CEI CANARIAS: Campus Atlántico & U. Las Palmas de Gran Canaria \\
\hline & Tricontinental & U. de La Laguna \\
\hline 2010 & Studii Salmantini & U. Salamanca \\
\hline 2011 & $\begin{array}{l}\text { Campus Euro mediterráneo del } \\
\text { Turismo y el Agua }\end{array}$ & U. de Les Illes Balears. U. de Girona \\
\hline 2011 & $\begin{array}{l}\text { Hidranatura. CEI en Gestión Eficiente } \\
\text { de Recursos Naturales }\end{array}$ & U. de Extremadura \\
\hline 2011 & ARISTOS. Campus Mundus 2015 & $\begin{array}{l}\text { U. Ramón LLull. U. de Deusto. U. Pontificia } \\
\text { de Comillas }\end{array}$ \\
\hline
\end{tabular}


Table 12.2 (continued)

\begin{tabular}{l|l|l}
\hline Call & CEI project & Universities \\
\hline 2011 & $\begin{array}{l}\text { CEI-MAR. Campus de Excelencia } \\
\text { Internacional del Mar }\end{array}$ & $\begin{array}{l}\text { U. de Cádiz. U. de Almería. U. de Granada. } \\
\text { U. de Málaga. U. de Huelva }\end{array}$ \\
\hline 2011 & $\begin{array}{l}\text { CEI Triangular E3. Los Horizontes del } \\
\text { Hombre }\end{array}$ & U. de Valladolid. U. de León. U. de Burgos \\
\hline 2011 & $\begin{array}{l}\text { CYTEMA. Campus Científico y } \\
\text { Tecnológico de la Energía y el Medio } \\
\text { Ambiente }\end{array}$ & U. de Castilla La Mancha \\
\hline 2011 & $\begin{array}{l}\text { Campus de Excelencia Internacional } \\
\text { Energía Inteligente }\end{array}$ & $\begin{array}{l}\text { U. Rey Juan Carlos. U. de Murcia. U. de } \\
\text { Extremadura. U. Politécnica de Cartagena }\end{array}$ \\
\hline
\end{tabular}

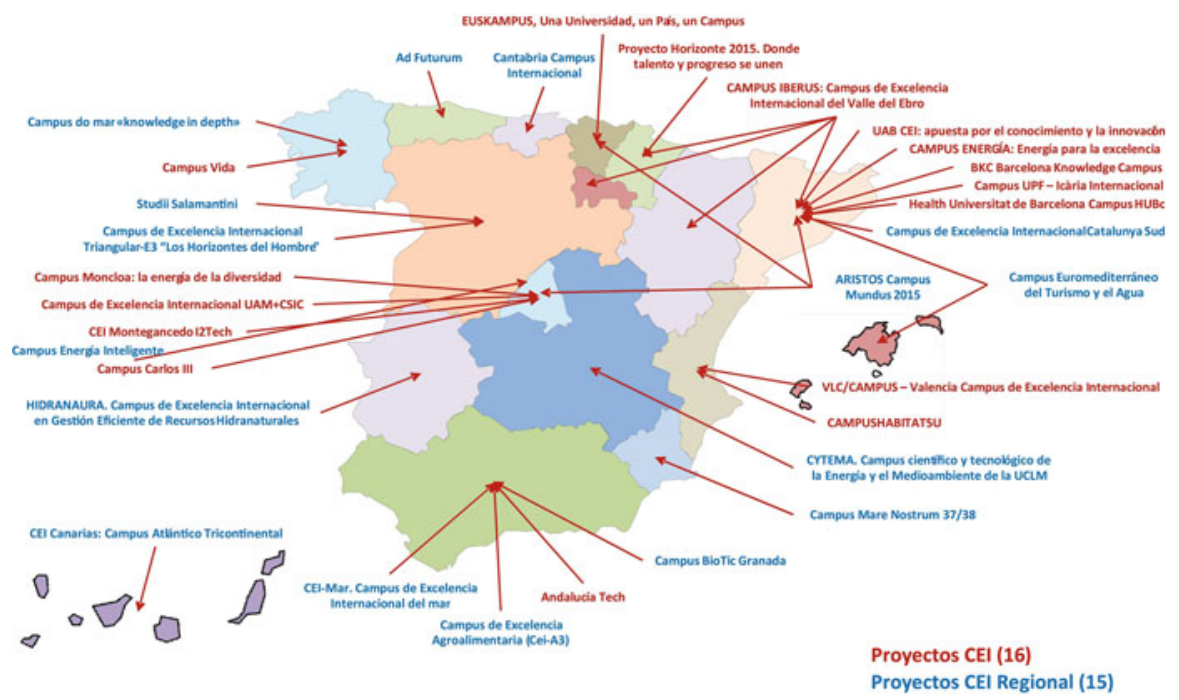

Fig. 12.4 Geographical distribution of CEI and CEIR

Table 12.3 Thematic distribution of the CEI/CEIR

\begin{tabular}{l|l}
\hline Knowledge field & No of CEI/CEIR \\
\hline Biomedicine/health & 18 \\
\hline Biotechnology & 11 \\
\hline Sea and marine sciences & 4 \\
\hline Natural sciences (physics, materials, chemistry) & 5 \\
\hline Heritage and culture & 7 \\
\hline Information and communication technologies & 6 \\
\hline Environment \& sustainability & 14 \\
\hline Energy & 8 \\
\hline Agriculture, food \& nutrition & 8 \\
\hline Social sciences \& humanities & 13 \\
\hline &
\end{tabular}


Table 12.4 Basic data of BKC and UAM + CSIC

\begin{tabular}{l|l|l|l|r}
\hline & BKC & Total BKC & & \\
\cline { 2 - 4 } & UB & UPC & UAM-CSIC & \\
\hline No of students & 33,813 & 21,842 & 55,655 & 29,802 \\
\hline No Bach. degrees & 30 & 17 & 47 & 76 \\
\hline No Master degrees & 71 & 61 & 132 & 129 \\
\hline No PhD programs & 39 & 30 & 69 & 45 \\
\hline No Professors & 2,562 & 1,528 & 4090 & 2,485 \\
\hline
\end{tabular}

Table 12.5 Position of universities in global ranking

\begin{tabular}{l|l|l|l}
\hline Ranking & UB & UPC & UAM \\
\hline ARWU & $201-300$ & & $201-300$ \\
\hline THE & $201-225$ & $351-400$ & $301-350$ \\
\hline QS & 187 & 350 & 206 \\
\hline ARWU Eng/Tech & & $151-200$ & \\
\hline ARWU Maths & & 151 & \\
\hline
\end{tabular}

institutions located in the Campus such as the Scientific Park of Madrid PCM and the Madrid Research Institutes IMDEA, with the goal of becoming the leading CEI in Spain in teaching, talent and research in four main areas: Biology and Biomedicine, Nanosciences \& Advanced Materials, Theoretical Physics \& Mathematics and Social Sciences, Law \& Humanities.

The basic indicators for each campus are given below (Table 12.4):

The position of the universities involved in the three projects in global rankings, i.e. Academic World Ranking of Universities (ARWU), Times Higher Education (THE) and QS World University Ranking (QS) is given in (Table 12.5).

\subsubsection{Rationale for the Alliance}

The key drivers and expectations are summarised in Table 12.6 for each CEI project.

\subsubsection{Process of Change}

The main measures to implement the three projects can be summarised as follows: 
Table 12.6 Rationale for alliances. Key drivers and expectations

\begin{tabular}{|c|c|c|}
\hline $\begin{array}{l}\text { CEI } \\
\text { project }\end{array}$ & Key drivers & Expectations \\
\hline \multirow[t]{5}{*}{ BKC } & $\begin{array}{l}\text { Achieve international excellence in } \\
\text { research, knowledge transfer and teaching }\end{array}$ & $\begin{array}{l}\text { Transformation of the campus through } \\
\text { innovation and specialization in three } \\
\text { areas: life sciences, social sciences and } \\
\text { technologies }\end{array}$ \\
\hline & $\begin{array}{l}\text { Become a campus open to the world and } \\
\text { committed to society and to economic and } \\
\text { social progress, responding and adapting } \\
\text { to the social, economic and strategic } \\
\text { needs }\end{array}$ & $\begin{array}{l}\text { Emerge as a magnet for attracting } \\
\text { international talent }\end{array}$ \\
\hline & $\begin{array}{l}\text { Make progress towards excellence from } \\
\text { the integration of activities favouring the } \\
\text { aggregation of both institutions }\end{array}$ & $\begin{array}{l}\text { Position the campus in different areas of } \\
\text { cutting-edge knowledge and research } \\
\text { such as Space, Nano and Environmental } \\
\text { Sciences as well as Entrepreneurship - } \\
\text { Increase the existing relationship } \\
\text { between research teams from both } \\
\text { universities with positive effects in } \\
\text { international rankings }\end{array}$ \\
\hline & $\begin{array}{l}\text { Become a catalyst and test-ground for } \\
\text { initiatives to be extended to the rest of the } \\
\text { university, acting as a tractor agent to } \\
\text { excellence }\end{array}$ & $\begin{array}{l}\text { Incentive for the university community to } \\
\text { continue the development of its goals }\end{array}$ \\
\hline & $\begin{array}{l}\text { Consideration of the CEI mention as a } \\
\text { recognition and intangible value motivat- } \\
\text { ing to further advance in excellence }\end{array}$ & $\begin{array}{l}\text { Contribute to the development of a sus- } \\
\text { tainable urban environment to make the } \\
\text { campus attractive. Open sports areas, } \\
\text { museums and cultural facilities }\end{array}$ \\
\hline \multirow[t]{2}{*}{$\begin{array}{l}\text { UAM } \\
+ \text { CSIC }\end{array}$} & $\begin{array}{l}\text { To achieve excellence in research in the } \\
\text { priority areas: biosciences, nanoscience } \\
\text { and materials science, mathematics and } \\
\text { theoretical physics. These areas must act } \\
\text { as tractors for other research areas }\end{array}$ & $\begin{array}{l}\text { To increase the international relevance of } \\
\text { the CEI, with an ambition to become the } \\
\text { leading Spanish CEI and achieving a } \\
\text { major jump in international rankings }\end{array}$ \\
\hline & $\begin{array}{l}\text { To get graduate and doctoral programs of } \\
\text { excellence and active talent attraction }\end{array}$ & $\begin{array}{l}\text { To achieve a close involvement with its } \\
\text { surroundings, in order to lead the social, } \\
\text { cultural and economic development of } \\
\text { the Madrid North area }\end{array}$ \\
\hline
\end{tabular}

\subsubsection{BKC}

- Attracting foreign students to $\mathrm{BKC} \mathrm{PhD}$ programmes through calls for postdoctoral grants

- Strengthening BKC's international reputation by introducing double bachelor and master degrees, and participating in European mobility programmes

- Increasing the range of Erasmus Mundus master degrees and programmes taught in English

- Signing strategic agreements with Chinese universities to set up the BKCnet network and enable students from that country to attend $\mathrm{BKC}$ courses 
- Offering education based on transversal competencies in entrepreneurship

- Participating in the creation of technology-based companies, as well as in the growth of spin-offs and start-ups, supporting these enterprises

- Consolidating a new model of business relations and strengthening the links with companies by launching the Innovation and Technology Centre at both universities

- Creating initiatives (nanos, geos, cosmos, and entrepreneurship) for cooperation/ coordination in specific research areas.

- Collaboration between international relations offices (joint international action, centres of excellence abroad)

- Reciprocal extension of "best practices" of the partner universities

- Creation of the management and communication unit, to increase the visualization of the BKC actions

\subsubsection{UAM + CSIC}

The first measure in developing the CEI UAM + CSIC was to set up a tool to steer the joint project between two organizations, UAM and CSIC, with different legal and organizational status.

The "Association for the Development of the CEI UAM + CSIC" was created to develop and follow up the execution of the shared strategies of excellence and internationalization. It is responsible for the set up and follow-up of the joint programmes defined in the project, the impulse of new strategic aggregations with knowledge transfer and research organizations, and the national and international communication and projection of the CEI. Several coordination commissions have been set up to follow up the work done in the project's sub-areas and for managing concrete activities.

The main actions have focused on creating or strengthening joint scientific infrastructures (platforms) or relationships (Biocampus), thus reinforcing the aggregation itself. Several initiatives of talent attraction for students (Graduate Programs of Excellence) and staff have also been launched.

\subsubsection{Funding}

Total funding allocated to the BKC project under the CEI 2009, 2010 and 2011 calls amounted to a total of 46,307,204 Euros, of which 39.2 M€ were loans and 7.1 M€ direct grants. The total funding allocated to the CEI UAM + CSIC since 2009 is 24 million Euros including specific grants under the Strengthening subprogram and loans under the Excellence program. In addition, existing resources at the University and CSIC are, at the end, behind the most relevant CEI initiatives. Most of that money has gone to new specific scientific infrastructures, but also common campus facilities such as the Plaza Mayor building. Other CEI income has been devoted to strengthen ongoing programs on graduate and $\mathrm{PhD}$ studies and on talent 
attraction. While being small, it must also be pointed out that investment has been made on several tools of the aggregation process itself, such as communication, branding or a specific website for the CEI.

\subsubsection{Engagement}

The engagement of staff and students in the aggregation process was driven by some key factors promoted by the BKC management such as creativity to contribute to the new campus, innovation and desire to learn from a new experience. This was soon to achieve an increased feeling of belonging to a cohesive urban campus with implications for the city's development. Collaboration was first established at postgraduate level, where a better use of the complementarity between the two universities could be made.

Within UAM + CSIC, the deployment of staff and students is being promoted by the CEI management, which provides information on the CEI developments on a regular basis, including the actions to foster participation and ownership by both academic and students. In addition, communication channels have been established to receive their suggestions and forward them to the responsible agents. Many have been addressed. This has enabled the development of some low cost actions that have nonetheless a high impact on the community. A clear example in this direction is an ongoing initiative for a Campus-wide ID card that will grant access to services provided by the different agents of the aggregation regardless of the specific group (UAM, CSIC or other) which the beneficiary belongs to.

\subsubsection{Resistance}

Within BKC, resistance to change stemmed from an initial mutual distrust of the other side and a distinction between "Us" and "Them", as well as from organizational and structural differences between a generalist university (UB) and a technical university (UPC) with certain divergent interests between the allies. Other resistance came from the parts of both universities excluded from the BKC project and from the rigidity of the present structures

No resistance to change has been so far detected in the CEI UAM + CSIC. Scientific and general collaboration between UAM and CSIC began many years ago and the two communities see the CEI as an opportunity to enhance their relationship, generate synergies and leverage existing resources.

\subsubsection{Progress and Outcomes}

The initial plans drawn in 2009 to build up "BKC" have been affected by the impact of the economic crisis reducing the budget available. Therefore, some of the largest, 
expensive structures are postponed or cancelled due to economic reasons. Some others have been redirected to make their building affordable. However, most actions in the initial project are progressing well, with some difficulties in implementing campus governance.

The major outcomes so far of the project are: a wide range of master degrees taught in English, new International Welcome Point, new international alliances, PhD grant programme, new scientific equipment, open campus, implementation of the energy consumption monitoring system, new study rooms with state of the art equipment, teaching activities aimed at young students, joint technology catalogue, joint Innovation and Technology Centre, Knowledge to Market programme, new social learning areas, new $\mathrm{PhD}$ School (technology area), full adaptation to the EHEA.

The assessment of the success of the BKC project, by the International Commission tasked with evaluating the progress of the CEI projects in 2011 and 2012 , indicates that $\mathrm{BKC}$ has made reasonable progress in creating a strong pole of innovation in support of the regional and national economy by realizing synergies through the joint activities of UB and UPC, giving more visibility to the new $\mathrm{BKC}$ brand and focusing on clear areas of strength (life sciences, social sciences and ICT).

The initial plans of CEI UAM + CSIC has to a large extent been achieved, resulting in the allocation of $88.6 \%$ of the budget for CEI specific grants at the end of 2012. The assessment of progress on the CEI made by the International Commission in 2012 shows good progress (by comparison with the assessment of "reasonable" progress for BKC) with sound advances in some areas such as teaching, research and development of the social model of the campus, and less progress in others, such as technology transfer and links with firms, as a consequence of the contraction of R\&D funds in Spain. More than 50 CEI-specific actions have been implemented or are under development since then. As a consequence, the project has consolidated itself with the support of all the relevant stakeholders, generating synergies and measurable results that are expected to increase in the near future.

A summary of the major strengths and problems for each project is given in Table 12.7.

\subsubsection{Conclusions and Lessons Learned}

A recent study ${ }^{13}$ concluded that the Campus of International Excellence Barcelona Knowledge Campus would occupy first position in the ARWU Shanghai ranking,

\footnotetext{
${ }^{13}$ Aggregate ranking of Spain's universities in the Shangai ranking (ARWU): Effect of autonomous communities and campuses of international excellence. El profesional de la información 2012, julio-agosto, v 21, n 4, ISSN: 1386-6710.
} 
Table 12.7 Summary of strengths and problems in each CEI project

\begin{tabular}{|c|c|c|}
\hline $\begin{array}{l}\text { CEI } \\
\text { project }\end{array}$ & Strengths & Problems \\
\hline \multirow[t]{7}{*}{ BKC } & $\begin{array}{l}\text { Joint internationalization activities and } \\
\text { overseas structures (China, Brazil) }\end{array}$ & $\begin{array}{l}\text { Financial problems with a disappointing } \\
\text { level of funding below the initial expec- } \\
\text { tations of the CEI program }\end{array}$ \\
\hline & $\begin{array}{l}\text { Increased interaction between UB-UB } \\
\text { and UB-UPC research groups }\end{array}$ & $\begin{array}{l}\text { Apparent change in the Ministry priori- } \\
\text { ties after the ministerial reorganization at } \\
\text { the end of } 2011\end{array}$ \\
\hline & $\begin{array}{l}\text { International postgraduate school to } \\
\text { improve teaching and research }\end{array}$ & \multirow{5}{*}{$\begin{array}{l}\text { It is considered that the potential of the } \\
\text { CEI concept to increase international } \\
\text { recognition and multiply and diversify } \\
\text { funding sources must help to overcome } \\
\text { these difficulties }\end{array}$} \\
\hline & Clear governance structure & \\
\hline & Support to entrepreneurship & \\
\hline & $\begin{array}{l}\text { Attention to the needs of disabled } \\
\text { students }\end{array}$ & \\
\hline & $\begin{array}{l}\text { Opening the CEI to VET through } \\
\text { apprenticeships scheme, especially in the } \\
\text { fields of entrepreneurship and } \\
\text { biomedicine }\end{array}$ & \\
\hline \multirow{5}{*}{$\begin{array}{l}\text { UAM } \\
+ \text { CSIC }\end{array}$} & Adaptation to the EHEA & \multirow{5}{*}{$\begin{array}{l}\text { Definition of the CEI's own governance } \\
\text { model, different from the ones followed } \\
\text { by the University or CSIC. The CEI } \\
\text { Association tries to clarify the mecha- } \\
\text { nisms of decision-making, offering a high } \\
\text { degree of transparency and accountability }\end{array}$} \\
\hline & $\begin{array}{l}\text { Teaching's improvement participating in } \\
\text { the program of the National Quality } \\
\text { Agency }\end{array}$ & \\
\hline & $\begin{array}{l}\text { Transformation of the campus into an } \\
\text { university city }\end{array}$ & \\
\hline & $\begin{array}{l}\text { Reform of research labs and scientific } \\
\text { infrastructures (Supercomputing, Food } \\
\text { and Genomic Platforms) }\end{array}$ & \\
\hline & $\begin{array}{l}\text { International Post-grade Program. } \\
\text { Attraction of talent }\end{array}$ & \\
\hline \multirow[t]{3}{*}{$\begin{array}{l}\text { UAM } \\
+ \text { CSIC }\end{array}$} & $\begin{array}{l}\text { Joint (UAM + CSIC) research institutes } \\
\text { and facilities in the priority areas }\end{array}$ & $\begin{array}{l}\text { Difficult current financial conditions and } \\
\text { their impact on university and research } \\
\text { budgets, limiting the actions that are } \\
\text { being launched }\end{array}$ \\
\hline & $\begin{array}{l}\text { Two "Severo Ochoa" Excellence Centres } \\
\text { out of a total of } 13 \text { in Spain }\end{array}$ & \multirow{2}{*}{$\begin{array}{l}\text { Slowdown in Spain's national CEI pro- } \\
\text { gram. Nevertheless the CEI UAM + CSIC } \\
\text { project has a strong internal logic and, } \\
\text { thus, will go on to a great extent inde- } \\
\text { pendently of external factors }\end{array}$} \\
\hline & $\begin{array}{l}\text { Three advanced grants and four starting } \\
\text { grants in ERC }\end{array}$ & \\
\hline
\end{tabular}

among the Spanish CEI, together with two CEI in Valencia, if they were a single university. In addition, if the BKC were a single university, it would be within the 150-200 range of the total ranking. The increase in visibility of a joint CEI UAM + CSIC visibility would result in joint teaching and research yearly budgets amounting to approximately 400 million Euros. If successful, this would result in much greater international recognition than currently achieved.

In fact, the project's logic and its key drivers stem from the internal recognition of the underlying relevance, interest and advantages that will be derived from its 
successful completion. An obvious advantage of aggregation is the much larger scope for recognition, visibility and, subsequently, attractiveness. Moreover, new investment will be smaller and much more efficient, a factor which is important under the current budgetary constraints.

A great advantage of the "CEI UAM + CSIC" is the previous long history of intense collaboration and shared successes between UAM and CSIC departments. This excellent springboard can only be enhanced and increased through collaboration with new partners, giving the project an important initial momentum and greatly leveraging its chances of success. The Association has a clear role in steering and smoothing the process, as well as reinforcing the project's brand image and increasing its visibility, both external but also internal. Building a wider awareness of the project among stakeholders and a strong communication plan are also key elements for its success.

\subsection{CEI Montegancedo: In-Depth Case Study of the Technical University of Madrid ${ }^{14}$}

\subsubsection{Rationale}

The Technical University of Madrid (UPM) is geographically distributed in five "ampuses" located in the "region of Madrid": Moncloa, Montegancedo, Campus Sur, Getafe and Valdelacasa (a future project of campus not initiated yet); there are also different engineering schools located at the centre of Madrid for historical reasons. $^{15}$

Two campuses of the UPM were selected to compete in the CEI programme (Moncloa and Montegancedo), looking for better chances for success in the evaluation process of the call and to be able to address very different institutional goals. Finally, the UPM obtained official recognition for the following two proposals presented in response to the open calls:

- Moncola Campus. It was jointly presented with the "Universidad Complutense de Madrid" (UCM) which acts as coordinator of the proposal. The thematic emphasis was placed on five "clusters" (S\&T domains) and a set of cross-cutting actions. The complementarity of both universities and the geographical location sharing the same campus was perceived as a unique opportunity.

- Montegancedo Campus. The proposal was presented exclusively by the UPM, but with the "aggregation" of many enterprises and public research centres. The

\footnotetext{
${ }^{14}$ This perspective complements the policy maker position expressed in the first part of the article in order to discuss the effect of the programme for the coordinator of the Campus in a technical university.

${ }^{15}$ They were located there well before the creation of the University itself in 1971 on the basis of pre-existent engineering schools.
} 
emphasis was placed on open technological innovation by using the information and communications technologies (ICT) as a driving tool in several S\&T domains addressed in the Campus.

This section focuses on the experience gained through the development of the CEI Montegancedo through the "I2_Tech" project. The CEI project was oriented towards cooperation with other entities to support user-driven open technology innovation, and the creation and location of new joint research centres or joint research labs with other public or private entities. More specifically, the objective was to increase the support for technological innovation jointly with the business sector, by using information and communication technologies (ICT) as a backbone and catalysing element empowering research activity. This became a fundamental axis of UPM's activity.

The UPM is committed to developing a "science-driven innovation" approach to support disruptive technological innovation in close interaction with research activity which the University is well prepared for. The CEI at Montegancedo is a key element of this strategy to become an open innovation ecosystem in itself where the UPM and other "aggregated entities" ("allies" in the CEI programme terminology) jointly generate value through the combination of teaching, research and innovation activities as outlined later in this chapter.

This vision is complemented by the need to infuse UPM's academic effort with an entrepreneurial attitude which extends to all students, at both undergraduate and postgraduate level, and faculty members. This vision should impact on the entire educational range of the university in addition to setting up specific courses or seminars on entrepreneurship.

When the UPM presented its proposal for CEI Montegancedo (UPM 2009), it was intended to build up a model of a university campus which is clearly different from other proposals under preparation by other Spanish universities. Even more important, the Campus was also being used as the basis for experimenting with new approaches for long-term cooperation with industry, based on high-level institutional support and shared commitments.

The "I2_Tech" proposal (implicit reference to the dual perspective of innovation and internationalization) submitted to the Excellence Programme was oriented towards the implementation of a user-driven open innovation scheme with the aggregation of private entities in order to accelerate the innovation process. In addition, the emphasis was placed on the exploitation and commercialisation of research results, considered as one of the areas of activity where the UPM can dramatically improve its performance in the near future.

Further to the identification of a set of actions and requesting funding for them, there was the institutional objective to affirm "excellence in technological innovation" as a common goal for the campus. This vision emphasizes the role which a technical university such as the UPM could play in Spain to accelerate technological innovation in a specific territorial context.

The UPM conceived the proposal from the deep conviction that higher education, research and innovation are closely linked, and public universities, above all 
those ones with a technological profile, should play a prominent role in promoting interactions between these dimensions; both through their own activity as well as in its social recognition. For Spain, and in the present context, stimulating science and engineering-driven innovation was identified as a very useful role of a technical university.

For this reason, the actions included in the "I2_Tech"-UPM proposal were aimed not only to develop this perspective from the thematic areas of the research centres located in the Campus (today or identified in the near future), but also to develop a set of distinctive features, including:

1. Multidisciplinarity in the scientific and technological approach necessary to address the solution of complex societal problems. The UPM assumed the high value that technology can offer to society in this context.

2. Open innovation model based on the creation of long-term and stable partnerships with other public and private entities across the value chain.

3. Support to entrepreneurship as a cross-cutting activity within a public university to accelerate a change of mentality among students and faculty members.

4. Extensive use of information and communications technology (ICT) by emphasising its role in strengthening the competitiveness of key sectors through the provision of advanced products and services.

5. The internationalisation of the innovation process related to the global exploitation of research results and the generation of $R \& D$ agreements with non-Spanish entities in a multicultural working context.

This model, when applied to a university campus, was considered as a novelty in the Spanish university context and it was chosen for building up the I2_Tech proposal submitted by the UPM to the Ministry's call for proposals. Figure 12.5 depicts the strategic view whereby many types of activities should be integrated under the three basic dimensions of the knowledge triangle. Some of those activities

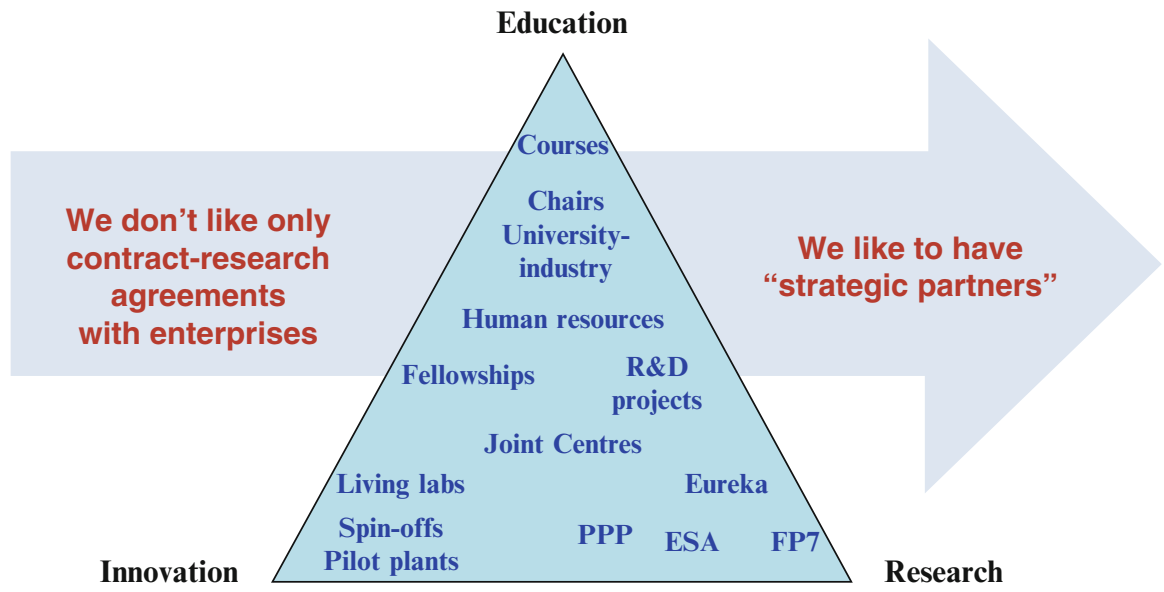

Fig. 12.5 Model of the Montegancedo campus from the knowledge triangle perspective 
existed in the Campus and others were specifically proposed for funding. This new approach was clearly recognised by the international panel which considered (citing the evaluation report) Montegancedo as "much further than a typical campus oriented to technology transfer".

The proposal which obtained official recognition was designed to convert Montegancedo into a Campus with a strong involvement of industry and other entities, through partnership with the UPM "focused on the support to technology innovation based on extensive use of ICT looking for new opportunities for collaboration at the international level.".

Currently, the statistical profile of the Montegancedo Campus is as follows: 500 researchers, 200 professors, 2,800 students, 8 research centres in operation, and the Faculty of Informatics. The Campus is also the location of advanced services on RTD and innovation (i.e. supercomputing, a set of living labs, technology demonstrators, support to technology innovation, business incubator, etc.). Globally, in the period 2005-2013, the total investment in the Campus exceeded $120 \mathrm{M} €$ (65\% of them through loans with $0 \%$ or very low interest rate) for infrastructures and scientific equipment.

Figure 12.6 depicts the units located on Campus near their main function. The list of research centres located in the Campus is as follows: CTB (Centre for Biomedical Technology), CBGP (Centre for Biotechnology and Plant Genomics), CEDINT (Centre for Home Automation), CESVIMA (Centre for Supercomputing and Visualization), CITA (Centre for Aerospace and Microgravity), COM (Centre for Open Middleware) and IMDEA software. A new one, CIESP (Centre for

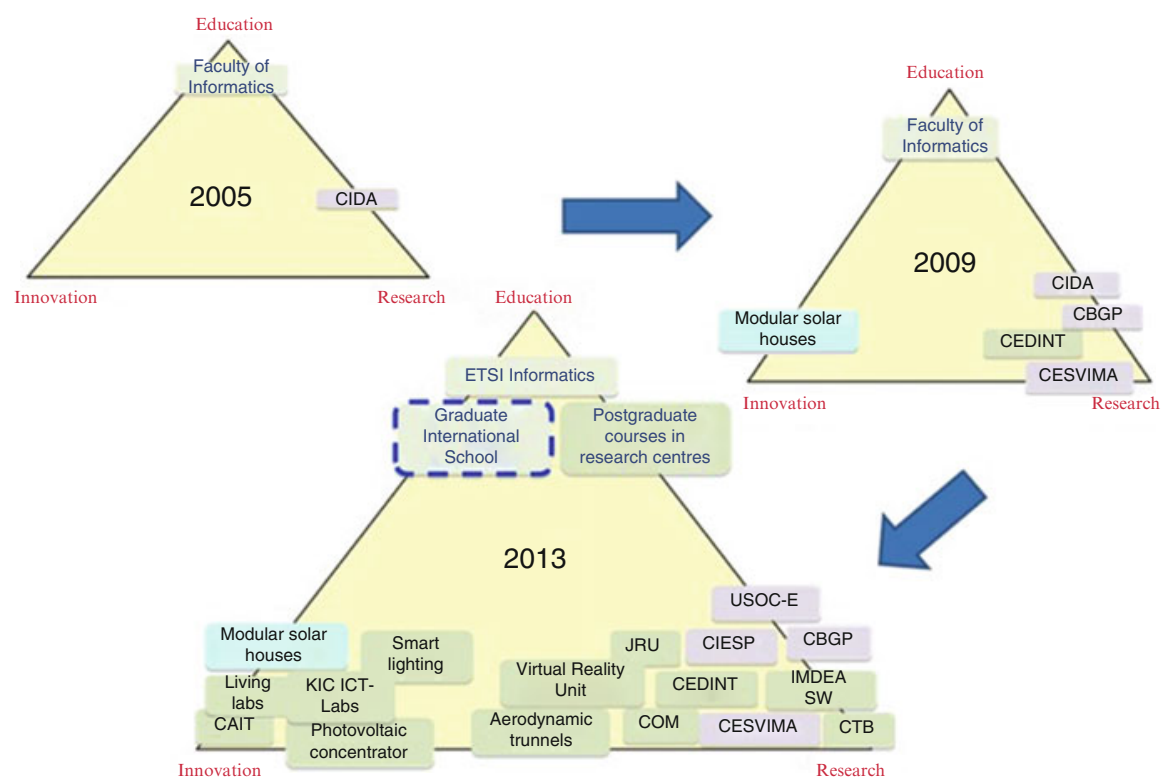

Fig. 12.6 Evolution of the CEI Montegancedo in the knowledge triangle 
preservation of the cultural heritage) jointly created with the UCM in cooperation with the CEI Moncloa is being located in 2013.

All of them belong to the UPM with the exception of the IMDEA Software which is a research centre supported by the regional government through a foundation structure (where the UPM participates as one of its stakeholders). Nevertheless, some of them were created as joint research centres with other entities (e.g. CBPG with the INIA, a public research centre on Agriculture, COM with the Santander Group, or with the agreement to create joint labs (e.g. CTB with the CSIC, and two universities UCM, and URJC). The CAIT (Centre for Technology Innovation) and the business incubator complete the set of units located in 2013.

\subsubsection{International Perspective of the Campus Montegancedo}

Participation in large international research projects with the industrial sector, as undertaken in the Seventh Framework Programme of the EU (FP7), the European Space Agency (ESA), etc., is a strong point of the UPM. More than the $35 \%$ of the UPM's FP7 participation relates to research groups located on the Montegancedo Campus. Furthermore, participation in other large international projects like "Blue Brain" (in the CTB) coordinated by the Ecole Polytechnique Fédéral de Lausanne (EPFL) in Switzerland, the FET Flagship on Human Brain, the Spanish node of the ICT-Labs knowledge and innovation community of the European Institute of Technology, or through the Foundation Bill \& Melinda Gates (in the CBGP) also provide a strong international networking profile in research activities.

In order to extend this international perspective, several agreements with other entities were signed to address the following aspects:

- To develop capacity to create joint labs in ICT or Biotech with other entities. As an example, the creation of the associated node of the IC-Labs (KIC-EIT) or the joint centre with Campinas were successful examples from this perspective.

- To design and implement joint graduate programmes (Master degrees in research centres) in cooperation with other non-Spanish entities. The setting up of the Masters in Bio-energy with UNICAMP (Brazil), or the Masters in translational clinical research with the Colorado University (USA), or participation in another Masters in Computer Science with the University of Toulouse (France), are examples embedded in this strategy.

- To accelerate the exploitation of research results at the international level. It also includes some agreements with foreign business incubators to help in the expansion of the spin-offs created by the UPM. Joint activities were carried out with the Technical University of Munich (TUM) and the Politecnico di Torino (POLITO). 
This strategy was also pursued through the signature of agreements with private firms to create joint ventures oriented towards the creation of joint labs, participation in large projects, or even the setting up of joint research centres. ${ }^{16}$

A specific programme for attracting international talent through the opening of post-docs positions (partly funded by People-FP7) in research centres, or pre-doc fellowships was mainly oriented to attracting foreign researchers. This vision was completed with the international recruitment of senior researchers from abroad. The agreement signed with the BBVA and the European Commission (COFUND scheme in the People programme) ${ }^{17}$ provided permanent positions for the creation of three new research groups on Campus. This example also demonstrates the opportunities open through fruitful public-private cooperation.

\subsubsection{The Role of the Private Sector}

The creation of strategic alliances with the private sector was considered as a basic element for the success of the "I2_Tech" proposal. Its rationale was based on the strong relationship and mutual trust with private companies which exists today between the UPM and the industrial sector in the R\&D activities. The institutional interest of the UPM should shift from the conventional project-to-project cooperation scheme (even if they are funded by international research programmes) to the implementation of strategic long-term alliances associated to the creation of joint research labs or units (Fig. 12.5).

Some strategic long-term agreements with private firms were signed to support this approach in connection to the research centres located on the Montegancedo Campus: with IBM in the field of high performance computing for computational biology, with INDRA in the area of medical ICT platforms, with Repsol for biofuels and simulation of pipelines, with the Santander Group in the area of open middleware, with Elekta in Magnetoencephalography, with "T-Systems" in virtual reality, with Zeiss in post-processing of microscopy images, with CISCO in the area of cloud computing and virtualisation, with Philips and LPI in smart lighting systems, with Accenture, CREANIA and e-Gauss in the support to entrepreneurship and spin-off creation, and with Telefónica, ATOS, BBVA and INDRA in the creation of a node of the ICT-Labs KIC of the European Institute of Technology (EIT).

Figure 12.7 schematically depicts the concept of open innovation ecosystem created in the CEI Montegancedo.

\footnotetext{
${ }^{16}$ Some examples were in the EU with Elekta and T-Systems, in the USA with IBM and LPI, in Brazil with Sinopec-Repsol, and smaller ones in other parts.

${ }^{17}$ Two consecutive projects in the FP7-People programme were approved: UNITE in 2010 and PILOT-INN in 2013 (for the whole UPM and not only for the Montegancedo Campus).
} 


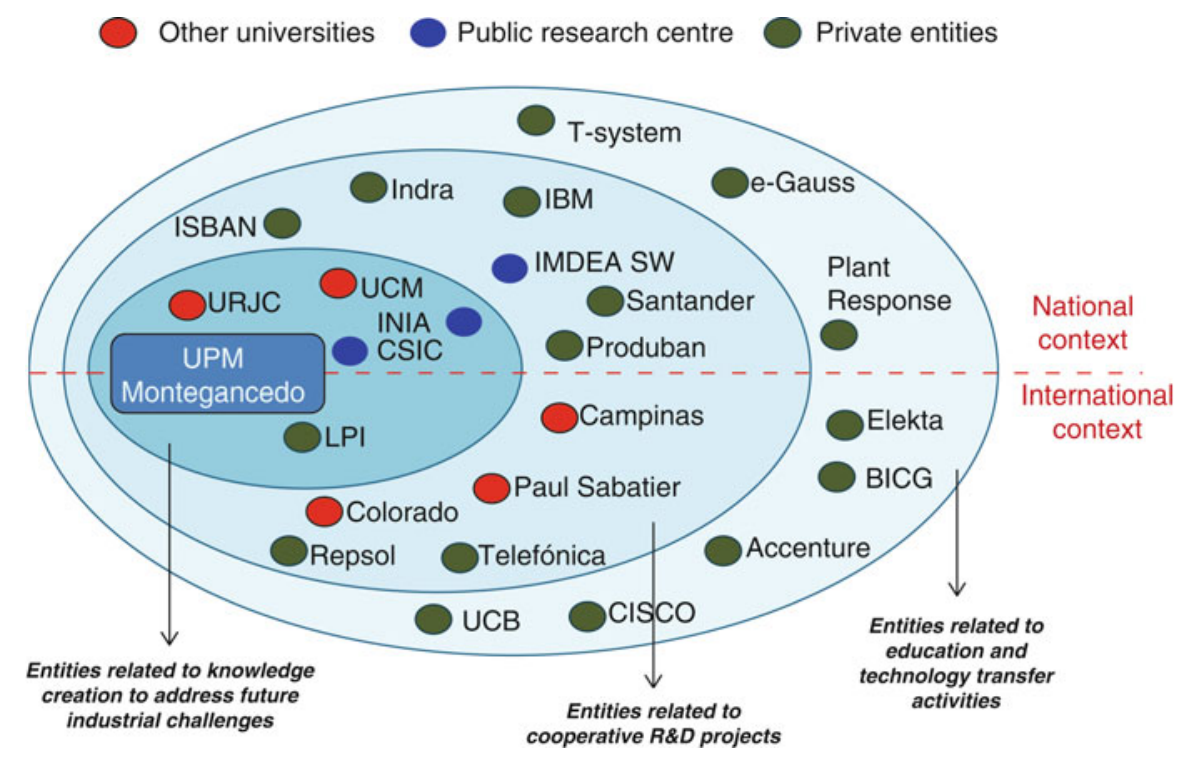

Fig. 12.7 Open innovation ecosystem of Montegancedo

In order to support formal interactions between the university authorities and the aggregated entities (a total of 25 public and private entities were formally aggregated in 2013), the UPM promoted the creation of an Advisory Council. By meeting regularly, and also by setting up specific working groups (in 2013 two working groups were created on Internationalisation and Technology Commercialisation), the Council became a useful instrument to exchange ideas and to prepare new actions in bilateral or multilateral formats.

It is too early to assess the validity of this approach but it is envisaged that the need to find flexible and operational easy mechanisms for the progressive introduction of aggregated units in the daily life of the Campus of Montegancedo will be achieved.

\subsubsection{Support Centre for Technology Innovation}

The UPM is required to improve the exploitation of research results (not only through the licensing of patents but also through the commercialisation of technologies developed by research groups or research centres) in those cases where the technology has not been developed for a specific company by using a contract research model. ${ }^{18}$

\footnotetext{
${ }^{18}$ Usually, contracts with third parties imply the transference of the property and/or the exploitation rights to the entity paying the research activity.
} 


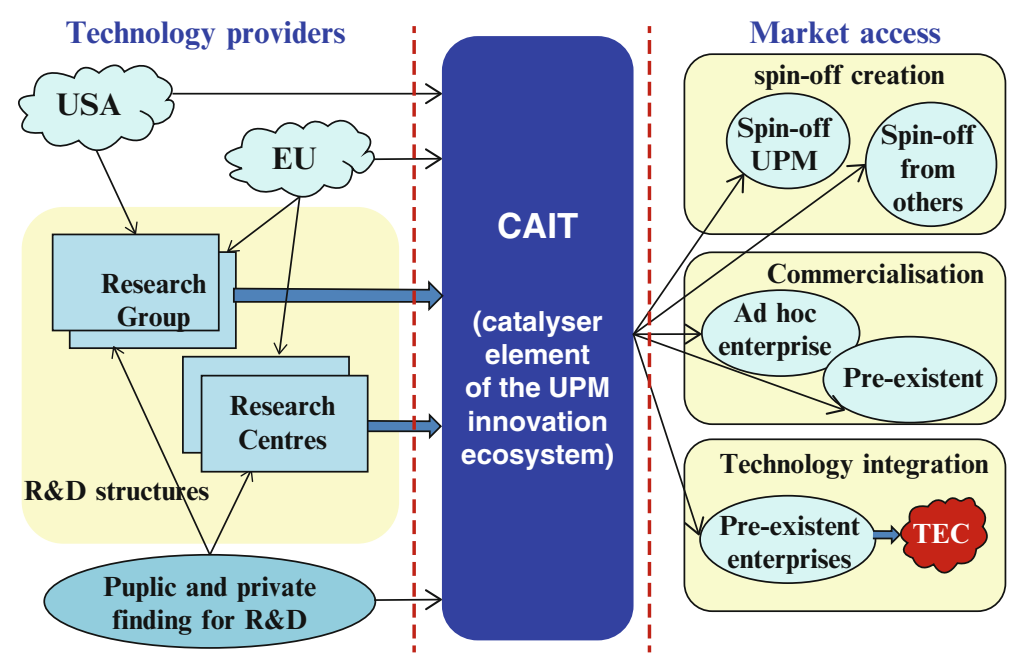

Fig. 12.8 Role of the CAIT in the UPM

Unfortunately, the results generated through research projects are immature and it is necessary to continue their development for a while until they reach a stage where the transfer to a company or the creation of a spin-off is possible based on a consolidated proof of concept. In order to mature promising technologies created at the UPM, the I2_Tech project proposed to create the "Centre for Support Technology Innovation" (CAIT) to catalyze this process. Figure 12.8 depicts its role as a bridge between technology providers and the access to market. The centre started its activities in 2013.

There is a natural/physical bridge between maturing research results, business ideas, and the creation of spin-offs or start-ups because CAIT was built physically connected to the present business centre and competences on spin-offs and business incubator constitute part of it.

During 2013 the main efforts focused on identifying and funding promising technologies through the launch of the "Fund for UPM Technology Commercialisation", which focuses on proof of concept for select UPM promising technologies. As Fig. 12.9 shows, many other activities are carried out in parallel to support maturity.

When technology matures (if possible, in less than 1 year), two options are possible:

1. to sell it to a third party (at the national or international technology market) as a single product or integrated with others, or

2. to create a spin-off company to exploit it. The first data on exploitation during the period 2012-2013 indicated a huge leap forward. 


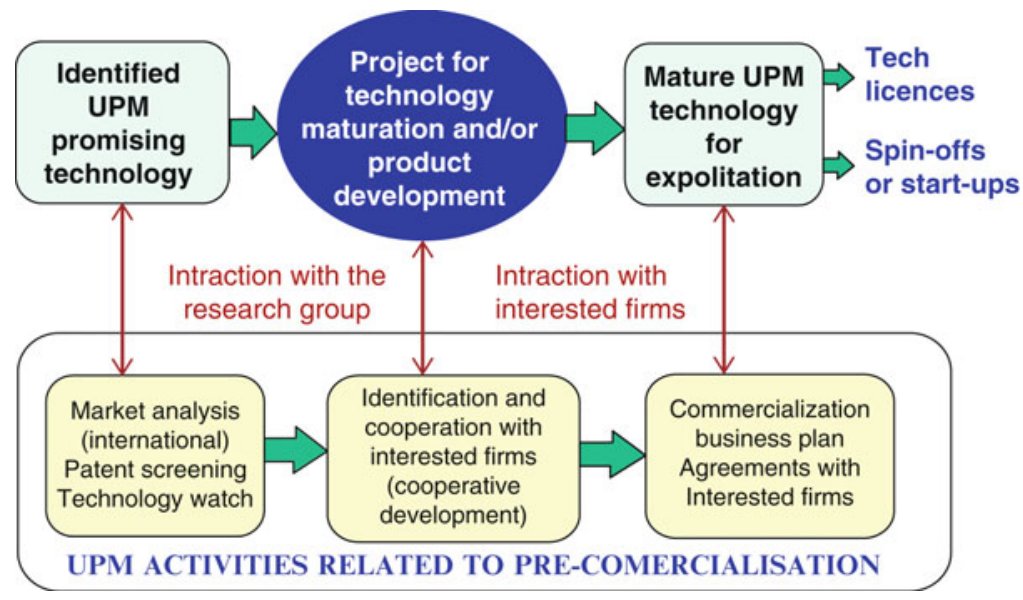

Fig. 12.9 Towards the exploitation of research results

\subsubsection{Horizontal Issues}

\subsubsection{Governance of the Aggregations}

The concept of "aggregation", as it was conceived in the Spanish Excellence Programme, is conceptually very powerful. Nevertheless, it is also very complex to implement from the decision making perspective. In short, the aggregation is not intended to substitute the decision-making processes currently in place, but to create another level which co-exists with the previous processes. The case of Montegancedo is easier because the aggregated entities do not decide at the global level although they influence its evolution.

Cooperation with the CEI Moncloa was supported in the magnetoencephalography system (located in $\mathrm{CTB}$ ) and the joint research centre on preservation of cultural heritage (CIESP). Additional joint activities will be launched in the near future.

One of the main challenges noted during implementation of CEI projects was in securing the involvement of the whole university. The concept of "campus" had a geographical context and the selection of some thematic domains made it impossible to incorporate all faculty members and schools in the main actions. ${ }^{19}$ Although some effort was made to develop cross-cutting activities, it is evident

\footnotetext{
${ }^{19}$ It was evident in successive calls of the programme that the ministerial interpretation of the geographical focus of "campus" was relaxed and, in the end, the borders of the concept of "campus" were blurred. Some of the awarded proposals included aggregations of universities located in several regions with a common goal.
} 
that many members of the community did not feel deeply engaged in the Campus of Excellence.

In the CEI Montegancedo the situation was easier because the type of actions were intentionally chosen to increase the opportunities for generating additional research or innovation activities with the industrial sector, and to exploit research activities carried out in other parts of the UPM. These activities would generate enough resources to reimburse the loans through the participation of research centres and also to re-distribute them to other research groups; however, it is too early to assess the level of attractiveness for the industry generated in this context.

\subsubsection{Concept of Excellence in Innovation}

As mentioned above, "excellence" can be applied to a set of university activities and it is not limited to the research perspective. Then, to measure the way that "excellence" in the chosen domains has improved after or as a consequence of its recognition as a "Campus of Excellence" should be a clear goal during the assessment of the benefits of the programme. Implicitly, it is assumed that the funding and the recognition would serve as an "accelerator" for obtaining the intended excellence in the valorisation of disruptive research results at the international level.

The evolution of patents, licences and royalties, and the generation of spin-offs in the last years are very positive. More specifically, more than 50 patents granted in 2012, with 17 spin-offs created and 12 licenses contracts represent a huge leap forward, where CEI Montegancedo is a key catalyser.

Does this evolution come from the funding in the CEI programme? We cannot affirm that it is the only cause, but we are sure that it has contributed to it by stimulating the signature of agreements with other entities, and the attraction of skilled human resources on the basis of the existence of sophisticated scientific equipment.

\subsubsection{Lessons Learned}

After 3 years, the programme has been (temporally) "frozen" by the incoming Spanish Government in 2012 but the follow-up of pre-existing grants is in progress and a decision about its future is still in discussion. Simultaneously, the economic situation of Spanish universities with sharp cuts in the funds received from regional governments is becoming more difficult and is forcing the re-planning of their strategic actions to ensure long-term sustainability. In many cases, the regional governments (this is the case for the region of Madrid) have not accepted the commitments derived from the long-term loans and these have to be covered by the universities themselves.

The evolution of the UPM will condition the future of Montegancedo. The proposal was defined before the global crisis and many activities were planned 
under the assumption that additional funds will be available (for instance, from S\&T Parks or from the regional government). The lack of additional calls, the hard conditions for accessing soft loans, and the removal of investments chapters are forcing the redefinition of activities and the need to pay considerable attention to increasing the revenues from international R\&D programmes, contracts with industry and the exploitation of scientific equipment and IP.

For the CEI Montegancedo, there are three main elements which will condition the evolution of the campus:

- Scientific consolidation of the new research centres located in the Campus. This is a very important element in enhancing its attractiveness for new researchers and to increase participation in international research consortia.

- Increasing the critical mass of students with an emphasis on post-graduate students. To compensate for the sharp increase in tuition fees a fellowship programme is being designed with the cooperation of the aggregated industries.

- Strengthening cooperation with industry and the exploitation of research results. In this respect, the CAIT could provide a very important framework for accelerating exploitation of IP assets.

In summary, the Spanish Programme on International Campus of Excellence constitutes an effort to promote the strategic modernisation process at universities even if the funding of the projects is mainly based on soft loans and strongly conditions the type of activities to be supported. The UPM, after obtaining the recognition of the two proposals oriented towards complementary goals, has a great opportunity to increase its international visibility and to accelerate its excellence in the context of the knowledge triangle. It should be the basis for its new strategic positioning in the international arena.

\subsection{Concluding Remarks}

After 3 years of operation, the participation of all the Spanish Public universities and 17 out of $29(59 \%)$ private universities, despite the fact that private universities are not eligible to receive loans through the autonomous communities, indicates that the CEI program is having a real impact on the configuration of the university landscape in Spain.

The impact is significant in terms of the following aspects:

- Providing additional funding to define and develop strategic processes to become a CEI in a 4 year period;

- Creating new teaching and research positions as well as campus managers;

- The internationalization of teaching and research activities;

- Increasing international attractiveness because of the CEI label;

- Promoting social awareness in relation to the universities' role in contributing to the economy recovery; 
- Supporting the strategic aggregation of universities, research and technological centres and firms;

- Building up knowledge ecosystems in specific thematic fields related with the social challenges;

- Promoting the role of universities in underpinning "creative cities" and "smart territories".

On the other hand, and not without difficulties, the CEI program modifies the model of "excellent university" showing that there is not a single model to achieve excellence. Each CEI is implementing the strategic plan and governance setup which allow them to deal with these new challenges:

- High quality in teaching, providing to students with the competences and skills needed for new jobs and innovation;

- Quality and relevance in frontier research in relevant areas to contribute to the solution of societal challenges (energy, food, environment, transport, etc.) and to the innovation needs of SMES;

- Hub in the International Networks of Knowledge;

- Positive impact in the socioeconomic environment, exchanging knowledge with businesses and society at large;

- Relevant in the process towards the shift to a sustainable knowledge-based economic model;

- Magnet for international talent and knowledge related investments.

In its present phase, the CEI program will continue to assess the progress of the existing CEI allowing for the dynamics of the Spanish university landscape until the CEI projects reach their end in 2015 and promoting additional funding to the Spanish University System, mainly through Public - Private Partnership schemes as the one already in place in the CEI program.

Open Access This chapter is distributed under the terms of the Creative Commons Attribution Noncommercial License, which permits any noncommercial use, distribution, and reproduction in any medium, provided the original author(s) and source are credited.

\section{References}

Barcelona Knowledge Campus. (n.d). [Online] Available at: http://bkc.ub.upc.edu/

Campus de Excelencia UAM - CSIC. (n.d). [Online] Available at: http://campusexcelencia.uamcsic.es/ss/Satellite/CampusExcelenciaUAM/es/home.htm

Commission of the European Communities. (n.d). Communication from the Commission COM (2006) 208 final "Delivering the modernization agenda for universities: Education, research and innovation".

Docampo, et al. (2012). Aggregate ranking of Spain's universities in the Shangai ranking (ARWU): Effect of autonomous communities and campuses of international excellence. $E l$ profesional de la información, 21(4), 428-432.

Instituto Nacional de Estadística. (2011). Estadística de Actividades de I+D. Madrid, Spain. 
Ministerio de Economía y Competitividad. (2012). Indicadores del Sistema espanol de Ciencia y Tecnología. Madrid, Spain.

Ministerio de Educación. (2008-2011). Balance de tres anos del programa Campus de Excelencia Internacional. Madrid, Spain.

Ministerio de Educación. (2010). Strategy university 2015. Modernizing the university. Madrid, Spain.

Ministerio de Educación. (2011-2012). Datos y Cifras del Sistema Universitario Curso. Madrid, Spain.

Organization for Economic Cooperation and Development. (2011). Education at a glance. Paris: OECD.

Rubiralta, M., \& Delgado, L. (2010). Developing international campuses of excellence. Paris: OECD.

Science, Technology and Competitiveness key figures report. (2008/2009). EUR 23608 EN.

Strategy University. (2015). Modernizing the University. June 2010. Ministry of Education, Spain.

Universidad Politécnica de Madrid. (2009). I2Tech. 2009 Project, Final proposal. http://www.upm.es/ sfs/Montegancedo/documentos\%202013/documentos\%20finales/objetivosEN_2013.09.16.pdf 